\title{
PERFORMANCE IMPROVEMENT OF MIXED FLOW PUMP IMPELLER THROUGH CFD ANALYSIS
}

\author{
Krishna Kumar Yadav ${ }^{1}$, V.K. Gahlot ${ }^{2}$ \\ ${ }^{1}$ Hydro Power Engineering, Department of Civil Engineering, MANIT Bhopal, Madhya Pradesh, India \\ ${ }^{2}$ Professor, Department of Civil Engineering, MANIT Bhopal, Madhya Pradesh, India
}

\begin{abstract}
Centrifugal pumps are the largest used hydraulic machine. However, the performance of centrifugal pump is generally not very good. Making them more efficient is a major challenge. The performance of the centrifugal pump greatly depends on its geometrical parameters and the vane profile. Computation fluid dynamics (CFD) has been found to be very good tool for numerical analysis of flow through complex system including centrifugal pumps. The present study deals with the performance analysis of a mixed flow type centrifugal pump designed centrifugal pump to deliver $0.25 \mathrm{~m}^{3} / \mathrm{s}$ water at a head of $20 \mathrm{~m}$ running at 1450 rpm using ANSYS CFX 14.0 software. Modeling of the pump unit has been done using PTC Cre-o 2.0 software. The performance of the pump was first determined using the initially obtained vane angles. The inlet vane angle and outlet vane angle are then varied to analyses the improvement in pump performance. The results shows that for an initial inlet angle $20.08^{\circ}$ and outlet angle $16.28^{\circ}$, the efficiency of the pump is $83 \%$.however, for an optimized angles at inlet and outlet as $20.16^{\circ}$ and $16.62^{\circ}$ respectively, the efficiency of pump raised to $88 \%$ thus showing an improvement in the performance of mixed flow pump.
\end{abstract}

Keywords: Computation Fluid Dynamics Analysis, mixed flow pump, overall efficiency

\section{INTRODUCTION}

A pump is a machine used to move liquid through a piping system and to raise the pressure energy of the liquid. Mixed flow pump is an example of a combination of radial and axial flow Large numbers of pumps are being used for various purposes such as irrigation, industrial applications, water supply schemes, fire fighting etc. huge amount of energy is consumed by these pumps. However, the performance of the pumps in general is not very good. To reduce the energy consumption, it is necessary that the performance of pumps improves. The losses namely, Hydraulic, leakage, disc friction and mechanical losses plays important role in performance of mixed flow pump. Hydraulic losses which include skin friction, eddy and separation losses in the suction nozzle, impeller, and volute can be minimized by changing the blade angle and using smooth surfaces .leakage loss can be reduced by using seal, interstage bushings. Disc friction loss is arising due to rotating of impeller in liquid and this can be avoided by controlled leakage flow between two surfaces and reduce the surface roughness. Mechanical loss is arising due to friction in bearing and stuffing boxes or mechanical seal. The performance of the mixed flow pump is greatly affected by the geometry of the impeller. It is also affected by the blade profile parameter like inlet angle, outlet blade angle, length of the blade and thickness of the blade.

Bacharoudi et al ${ }^{[1]}$ had presented the influence of the outlet blade angle on the pump performance with the help of CFD simulation. The study showed that the performance curve becomes smoother and flatter as the outlet blade angle increased. It has been reported that while operating at nominal capacity, the head developed by the pump increases by more than $6 \%$, when outlet blade angle was increased from $20^{\circ}$ to $50^{\circ}$. Chaudhari et al ${ }^{[2]}$ analyzed the mixed flow impeller with the help of CFD. It has been reported that the head of the impeller is enhanced by changing the inlet, outlet blade angle and the number of blade.

Gahlot and Nyiri ${ }^{[3]}$ suggested the one-by-one design procedure for designing of radial, Francis, and mixed flow pumps. For mixed flow pump design, numbers of relationships have been suggested based on the practical experience. Gundale et al ${ }^{[4]}$ analyzed is to verify the performance of centrifugal pump at best efficiency point. Manikandan et al [5] reported that the leakage loss contributed about $7 \%$ of the total flow in the mixed flow pump. By the computational fluid dynamics analysis, the internal flow pattern, pressure and velocity contour were found. Manivannan et al ${ }^{[6]}$, analyzed the mixed flow impeller with the help of CFD detailed simulation of flow in impeller was found. It was reported that the best efficiency of the mixed flow impeller was found by changing inlet and outlet blade angle. Nataraj et al ${ }^{[7]}$ studied the Taguchi's parametric design concept for performance enhancement of centrifugal pump. Eight virtual model of impeller were selected by different four parameters. The optimum condition of four operating parameter was found by simultaneous optimization. Kumar et al ${ }^{[8]}$ have given a c++ program using point-by-point method. Francis type mixed flow pump had been designed along with the mean streamline at the given operating conditions. S. Rajendran el $a l^{[9]}$ studied the impeller of centrifugal pump flow pattern, pressure distribution in the blade passage, blade loading and pressure plots by using ANSYS-CFX. Urankar Swapnil, Shivashankar H.S., Gupta ${ }^{[10]}$ have reported the impeller and 
volute designed by Walter K Jekat method and error triangle method. The design was further modified by taking equal divisions and varying vane inlet angle from hub to shroud. Performance of model has been analyzed in CFD tool CFX at different flow rates. It was found that increase in efficiency was due to little twist provided at the leading edge of the vane through varying the leading edge angle from hub to shroud and good results have been found by small modification in the vane.

\section{PUMP SPECIFICATIONS}

\subsection{Impeller Geometry}

In present work, for a pump which would develop $20 \mathrm{~m}$ head at a flow rate of $0.25 \mathrm{~m}^{3} / \mathrm{s}$ running at $1450 \mathrm{rpm}$, detailed geometric parameters have been calculated. The active pump components of mixed flow pump i.e. an impeller and a volute casing. Parameterization was done through reducing number of controlling geometric variables, to investigate their individual or combined effects on the flow and the impeller performance. After parameterization mixed flow pump impeller can be represented by small number of parameters. The values of the parameters are given in Table 1.

Table-1: calculated dimensions of mixed flow impeller

\begin{tabular}{|l|l|}
\hline Parameter & Size \\
\hline Impeller inlet diameter $\mathrm{D}_{1}$ & $169 \mathrm{~mm}$ \\
\hline $\begin{array}{l}\text { Impeller Outlet diameter } \\
\mathrm{D}_{2}\end{array}$ & $307 \mathrm{~mm}$ \\
\hline Blade width at inlet $\mathrm{b}_{1}$ & $112 \mathrm{~mm}$ \\
\hline Blade width at outlet $\mathrm{b}_{2}$ & $64.5 \mathrm{~mm}$ \\
\hline Blades number & 6 \\
\hline Vane angle at inlet $\beta 1$ & 21.08 \\
\hline Vane angle at outlet $\beta_{2}$ & 16.28 \\
\hline
\end{tabular}

\section{METHOD FOR CONSTRUCTING THE VANE}

\section{SHAPE}

\subsection{Point by Point Method}

It can be used for double curvature blades with some additions method as described here.

Consider a small segment $\mathrm{DD}_{1}$ of a stream line $\mathrm{A}_{1} \mathrm{~A}_{2}$ on the meridional plane. Real length of $\mathrm{DD}_{1}$ is $\mathrm{EE}_{1}$ as shown in the side elevation and is represented by segment $F_{1}$ in plan. In triangle $E_{1} G$, the angle $G$ is a right angle and $\angle E_{1} E G$ will be equal to $\beta$. Then

$$
E G=\frac{E_{1} G}{\tan \beta}=\frac{d e}{\tan \beta}
$$

The projection of segment EG of the concentric circle is HF.

$$
H F=r d \theta=\frac{d e}{\tan \beta} \quad \mathrm{d} \theta=\frac{\mathrm{de}}{\mathrm{rtan} \beta}
$$

Integrating above Esq. and multiplying by $180 / \pi$, gives the central angle in degrees i.e.

$$
\theta=\frac{180}{\pi} \int_{0}^{e} \frac{d e}{r \tan \beta}
$$

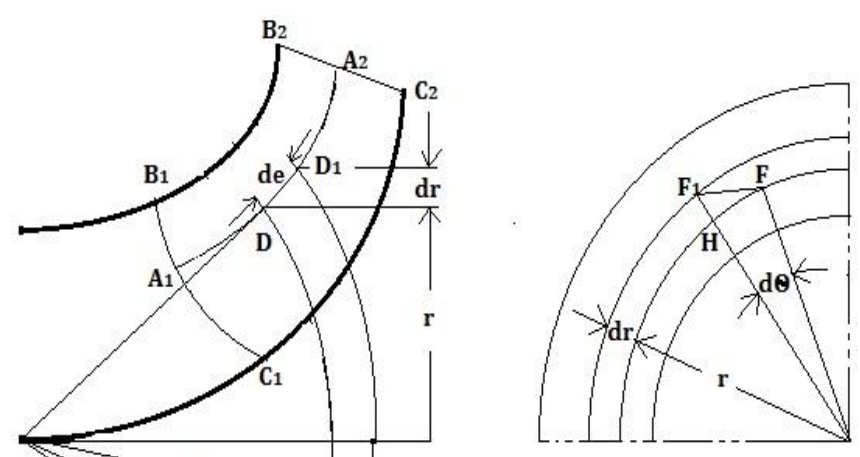

The values of $\theta$ and e are measured from a point starting from the inlet edge. As the relation between $\beta$ and $r$ and $e$ is not known in the form of an equation, integration is carried out numerically assuming finite increments $\Delta \mathrm{e}$.

After determining values of angle $\theta$ and radius $r$ at each point, the stream line is plotted in the plan view. Other stream lines are also determined in a similar way.

This method gives a blade surface which is the middle surface between the fronts and back faces of the blade. If the blade is thin and of constant thickness, which is generally the case, it can be assumed that the surface plotted is the front face of the blade and the other surface can be drawn.Fig. 2 shows a model of the pump impeller.

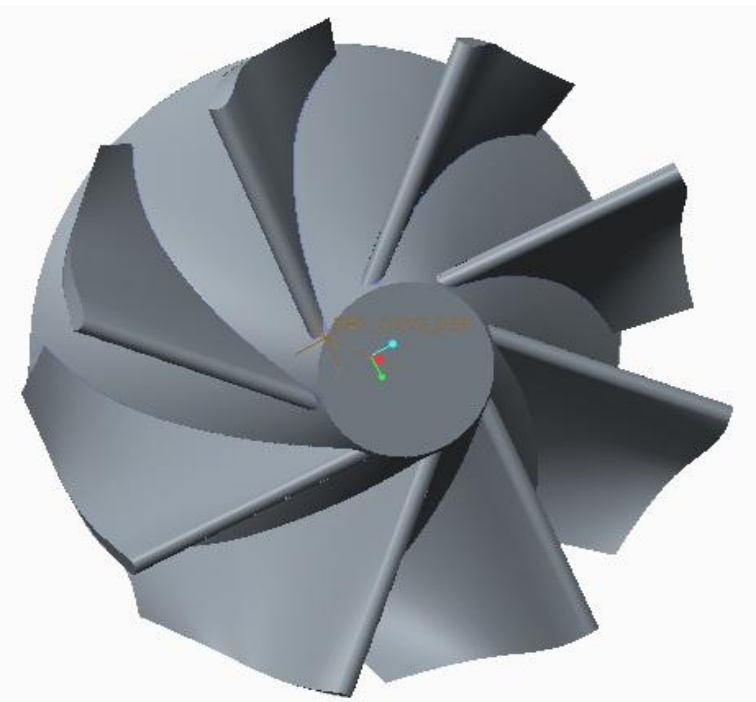

Fig-2: Model of Mixed Flow Impeller 


\section{METHODS OF CALCULATING VOLUTE CASING}

\subsection{Principle of Constant Moment of Momentum}

According to this principle, the moment of momentum remains constant at different sections.

$$
\mathrm{M}=\mathrm{C}_{\mathrm{u}} \mathrm{r}=\mathrm{C}_{\mathrm{u} 3} \mathrm{r}=\mathrm{constant}
$$

\subsection{Principle of Constant Mean Velocity}

It is widely used principle. The calculation of volute dimensions using this principle is considerably simpler.

The discharge at any section of the volute is equal to

$$
Q_{\varnothing}=\frac{Q \times \emptyset^{\circ}}{360^{\circ}}
$$

Area of volute at any other section is obtained as,

$$
A_{\varnothing}=\frac{Q_{\varnothing}}{C_{3}}=\frac{Q \times \emptyset^{\circ}}{360^{\circ} \times C_{3}}
$$

Where $\mathrm{C}_{3}$ is mean velocity in volute and $\varphi$ is central angle.

Fig. 3 shows the view of the volute casing of the pump

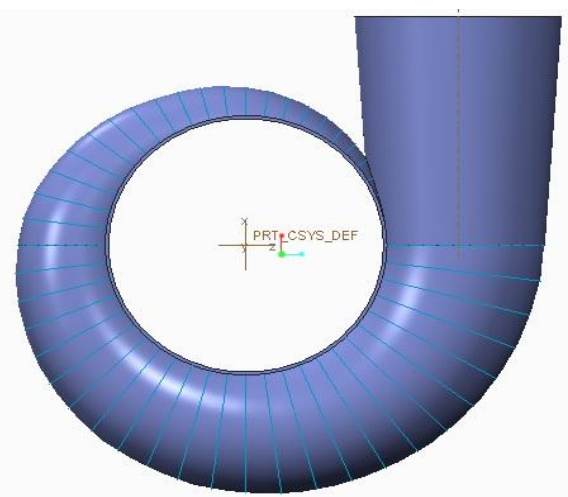

Fig-3: Model of casing

\section{MESHING OF PUMP}

Table-2: Mesh information of pump assembly

\begin{tabular}{|l|l|l|l|l|}
\hline $\begin{array}{l}\text { Total } \\
\text { elements }\end{array}$ & $\begin{array}{l}\text { Total } \\
\text { nodes }\end{array}$ & TRI_3 & TETRA_4 & LINE_2 \\
\hline 6308545 & 1054466 & 176148 & 6124041 & 8116 \\
\hline
\end{tabular}

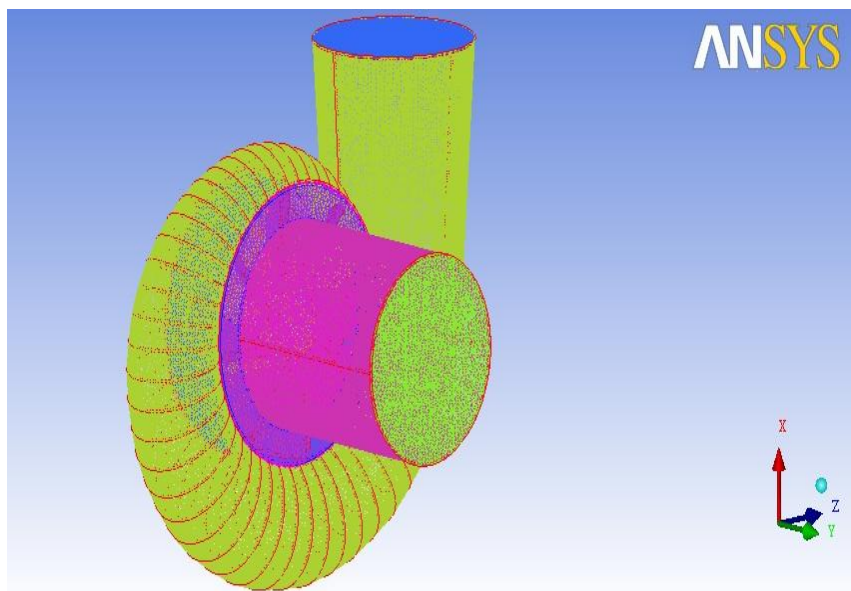

Fig-4: meshing of pump

\section{BOUNDARY CONDITIONS}

Mixed flow pump impeller domain is considered as rotating frame of reference with a rotational speed of $1450 \mathrm{rpm}$. The boundary condition was $1 \mathrm{~atm}$ at inlet and $250 \mathrm{~kg} / \mathrm{s}$ at outlet, $1450 \mathrm{rpm}$. The working fluid in the pump is water at $25^{\circ} \mathrm{C}$. $\mathrm{k}-\varepsilon$ turbulence model with turbulence intensity of $5 \%$ is considered.

\subsection{Velocity Stream Contour}

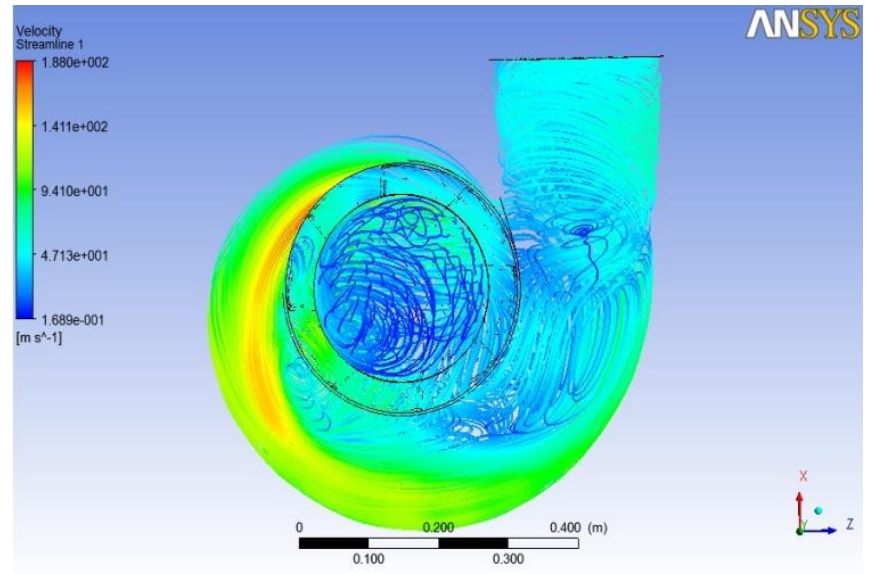

Fig-5: Velocity Stream Contour

\subsection{Pressure Contour}

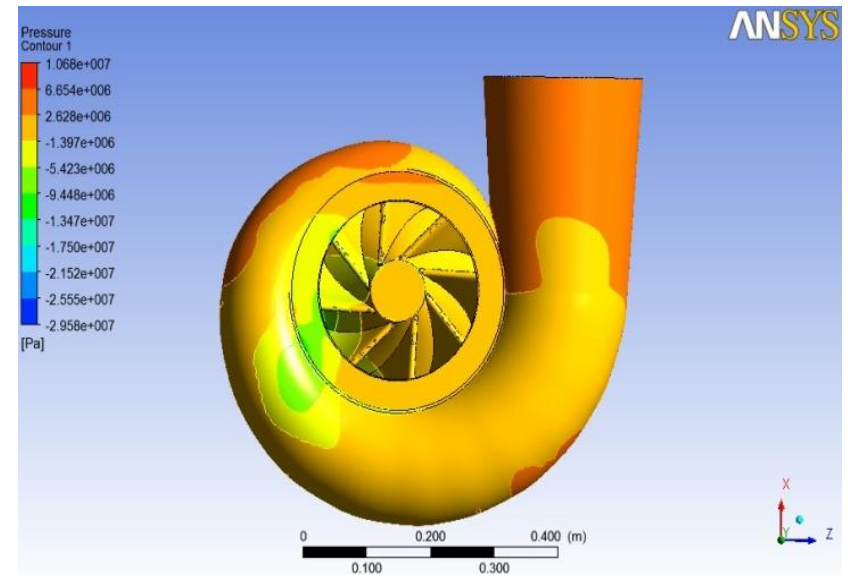

Fig-6: Pressure Contour 


\section{RESULTS}

Inlet power $=2 \pi \mathrm{NT} / 60 * 1000$,

Inlet power $=2 \pi * 1450 * 388.122 / 60 * 1000=58.934 \mathrm{~kW}$

Outlet power $=\left(\mathrm{P}_{0}-\mathrm{P}_{\mathrm{i}}\right) * \mathrm{Q} / 1000$

Outlet power $=(215916.8-17900.8) * 0.25 / 1000=49.504 \mathrm{~kW}$

Overall efficiency $=$ (outlet power / Input power $)$

$$
=49.504 / 58.934=0.84
$$

Table-3: Variation of efficiency

\begin{tabular}{|l|l|l|}
\hline Sr.No & Description & TYPE-MF2525 \\
\hline 1 & Efficiency of pump & $83 \%$ \\
\hline 2 & Efficiency (CFD) & $84 \%$ \\
\hline 3 & $\begin{array}{l}\text { Percentage } \\
\text { Variation }\end{array}$ & 1.1904761 \\
\hline
\end{tabular}

\section{OPTIMIZATION OF RESULTS}

\subsection{Existing Impeller Data}

Outlet Angle: $16.28^{\circ}$

Inlet Angle: $21.08^{\circ}$

\subsection{Optimization for Outlet and Inlet Blade Angle}

Table-4: Optimization of Outlet and Inlet Blade Angle

\begin{tabular}{|l|l|l|l|}
\hline Impellers & $\begin{array}{l}\text { Outlet } \\
\text { Blade Angle }\end{array}$ & $\begin{array}{l}\text { Inlet Blade } \\
\text { Angle }\end{array}$ & $\begin{array}{l}\text { No. of } \\
\text { Blades }\end{array}$ \\
\hline Impeller 1 & $16.62^{\circ}$ & $20.16^{\circ}$ & 8 \\
\hline Impeller 2 & $16.28^{\circ}$ & $21.08^{\circ}$ & 6 \\
\hline Impeller 3 & $16.24^{\circ}$ & $21.08^{\circ}$ & 8 \\
\hline Impeller 4 & $16.24^{\circ}$ & $21.08^{\circ}$ & 6 \\
\hline Impeller 5 & $16.20^{\circ}$ & $22.14^{\circ}$ & 8 \\
\hline Impeller 6 & $16.20^{\circ}$ & $22.14^{\circ}$ & 6 \\
\hline Impeller 7 & $16.13^{\circ}$ & $23.40^{\circ}$ & 8 \\
\hline Impeller 8 & $16.13^{\circ}$ & $23.40^{\circ}$ & 6 \\
\hline
\end{tabular}

\subsection{Results from Optimization}

Table-5: Result Table

\begin{tabular}{|l|l|l|l|}
\hline Impellers & $\begin{array}{l}\text { Inlet } \\
\text { power } \\
(\mathrm{KW})\end{array}$ & $\begin{array}{l}\text { Outlet } \\
\text { power } \\
(\mathrm{KW})\end{array}$ & Efficiency \% \\
\hline Impeller 1 & 60.120 & 52.910 & 88 \\
\hline Impeller 2 & 58.934 & 49.504 & 84 \\
\hline Impeller 3 & 59.350 & 51.030 & 86 \\
\hline Impeller 4 & 58.680 & 46.944 & 80 \\
\hline Impeller 5 & 59.680 & 50.728 & 85 \\
\hline Impeller 6 & 57.781 & 44.492 & 77 \\
\hline Impeller 7 & 57.949 & 45.432 & 78.4 \\
\hline Impeller 8 & 57.042 & 39.929 & 70 \\
\hline
\end{tabular}

\subsection{Efficiency Vs Mass Flow Rate}

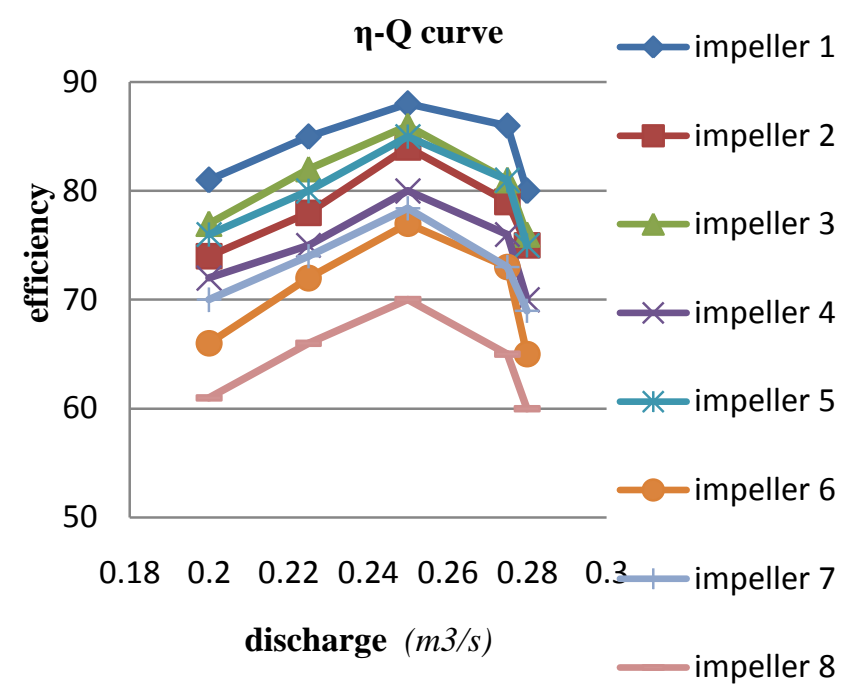

Fig-7: Efficiency Vs mass flow rate

Maximum efficiency obtained at flow rate $0.25 \mathrm{~m}^{3} / \mathrm{s}$ for all mixed flow pump

\section{CONCLUSION}

Improvement of the performance for mixed flow pump is simulated by decreasing the inlet blade angle and increasing the outlet blade angle. It was found that overall efficiency of mixed flow pump is increased by $5.68 \%$. Overall efficiency of pump increases with number of blade in mixed flow pump impeller. Performance of the mixed flow pump impeller also increases as outlet blade angle increases while inlet blade angle decreases and outlet pressure is also increases. Optimum efficiency was obtained at 8 blades at outlet angle, $16.62^{\circ}$ and inlet angle, $20.16^{\circ}$.

\section{ACKNOWLEDGEMENTS}

The authors thank the head of department of Civil Engineering and Director, MANIT, Bhopal.

\section{REFERENCES}

[1]. Bacharoudis, E. C., Filios, A. E., Mentzos, M. D., \& Margaris, D. P. (2008). "Parametric study of a centrifugal pump impeller by varying the outlet blade angle". Open Mechanical Engineering Journal, 2, 75-83.

[2]. Chaudhari, S. C., Yadav, C. O., \& Damor, A. B. "A comparative study of mix flow pump impeller cfd analysis and experimental data of submersible pump".International Journal of Research in Engineering \& Technology (IJRET) ISSN, 2321-8843.

[3]. Gahlot V.K and Nyiri A. (1993), "Impeller Pumps, Theory and design",M.A.C.T,Bhopal.

[4]. Virajit A. Gundale, S.A. PATIL 'Improvement in the Design of Radial type Vertical type Submersible open well pumps impeller using CFD'.

[5]. Manikandan, J., Senthil, V., \& Nagarajan, S. (2012). "Performance Evaluation of Mixed Flow Pump using 
Computational Fluid Dynamics". European Journal of Scientific Research, 80(4), 479-486.

[6]. Manivannan, A. (2010)." Computational fluid dynamics analyses of a mixed flow pump impeller. International Journal of Engineering, Science and Technology,2(6).

[7]. Nataraj, M., \& Arunachalam, V. P. (2006). "Optimizing impeller geometry for performance enhancement of a centrifugal pump using the Taguchi quality concept". Proceedings of the Institution of Mechanical Engineers, Part A: Journal of Power and Energy, 220(7), 765-782.

[8]. Kumar, P., Tiwari, H. L., Prashad, V., \& Gahlot, V. K., "Design of Francis type mixed flow pump impeller using c++". Journal of Engineering Research and Studies E-ISSN, 976, 7916.

[9]. Rajendran, S., \& Purushothaman, K. (2012, May). "Analysis of a centrifugal pump impeller using ANSYSCFX".In International Journal of Engineering Research and Technology (Vol. 1, No. 3 (May-2012)). ESRSA Publications.

[10]. Urankar, S., Shivashankar, D. H., \& Gupta, S. (2012). "Design and CFD analysis of single stage, end suction, radial flow centrifugal pump for mine dewatering application".

\section{BIOGRAPHIES}

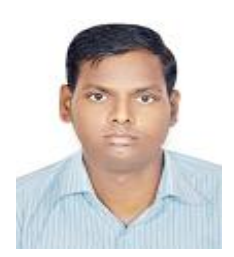

Krishna Kumar Yadav is a post graduate student of 2015 in hydro power engineering, MANIT, Bhopal

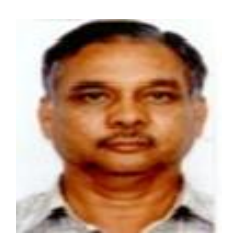

V.K Gahlot, Professor, Department Of Civil, MANIT, Bhopal. 